\title{
Exploring the Nature of Information Systems Development Methodology: A Synthesized View Based on a Literature Review
}

\author{
Daniela Mihailescu ${ }^{1}$, Marius Mihailescu ${ }^{2}$ \\ ${ }^{1}$ Jönköping International Business School, Jönköping, Sweden; ${ }^{2}$ School of Economics and Management, Lund University, Lund, Sweden. \\ Email: \{daniela.mihailescu, marius.mihailescu\}@ihh.hj.se
}

Received July $18^{\text {th }}, 2009$; revised February $25^{\text {th }}, 2010$; accepted April $16^{\text {th }}, 2010$.

\begin{abstract}
New Information Systems Development Methodologies (ISDMs) are suggested in the belief that their deployment would be beneficial to consultants in their work. A large number of ISDMs already exist but their value has been questioned and at the same time new methodologies continue to be introduced in an attempt to support and improve the practice of information systems development work. What is not always clear from current studies is that ISDM is a multi-perspective and cross-discipline phenomenon. Although a large amount of knowledge of ISDM is available, different disciplinary interests have resulted in fragmented assessments of it. This paper intends to identify theoretical perspectives applied in the conceptualization of ISDM. A review of the literature on ISDM was conducted and four different theoretical perspectives were identified: 1) system, 2) structure, 3) innovation, and 4) knowledge. While each perspective provides various overarching depictions of ISDM, the synthesized view of ISDM provided in this study reveals the complexities and ambiguities of a multifaceted phenomenon such as ISDM. Suggestions for an alternative conceptualization of ISDM are provided in an attempt to facilitate the investigation of ISDM.
\end{abstract}

Keywords: Information Systems Development Methodology, CASE Tools, Software Process Innovation, Literature Review

\section{Introduction}

In response to the pressure for more efficiency and effectiveness as well as flexibility and quality in Information Systems Development (ISD), new development models and methods, such as rapid product development, agile software development, and component-based development, have been suggested and are considered to be beneficial to consultants in their work. Yet, the quality of IS continues to be problematic, resulting in various outcomes and, once again, calling into question the value of the new information Systems Development Methodologies (ISDM). What is not always clear from current IS studies is the fact that ISDM represents a multi-perspective and cross-level phenomenon of study. In line with other authors [1,2], it is these authors' contention as well that ISDM have a central role in implementing or designing IS and educating tomorrow's professionals. At the same time, the opinion of these authors is that existing descriptive and fragmented approaches to studying ISDM provide contradictory results, on the one hand reducing the likelihood of understanding and hence of supporting the design of constantly evolving systems, on the other hand limiting the relevance and value of our theories and educational programs.

\section{Challenging Issues Related to ISDM}

The history of ISDM goes back to the 1960s and to the use of computers by businesses and the emergence of business applications, which represented a novel area of interest registering a rapid expansion [3]. Since then, the study of ISDM has attracted researchers across a range of research fields offering a rich set of descriptions and explanations of the ISDM phenomenon. Considerable attention from practitioners and several research streams has contributed to an impressive knowledge base for efficient and effective ways of developing information systems (IS) which over the years have been formalized and incorporated in a vast number of generic ISDM. Despite divergent opinions regarding the terminology and related semantic aspects, ISDM is considered to represent a collection of interrelated components aimed to support and improve the ISD practice [4,5]. In spite of these efforts, the ISD continues to be problematic and 
hence the significance of the methodological assumptions and, implicitly, ISDM is questioned as well.

The understanding of ISDM and its value has changed over the years from being a panacea for ISD, if used in a prescriptive and consistent way, to being a necessary but insufficient means in the development of IS [6,7]. Moreover, some of them are considered unsuitable for analyzing, designing and managing unpredictable situations characterized by complexity and uncertainty [8,9]. Additionally, ISDMs are often considered unsuitable for some individuals and settings, and similar ISDMs in similar settings apparently yield distinctly different results $[3,9]$. While some authors are critical to the exaggerated emphasis placed on ISDM and suggest the introduction of improvisation [10] or amethodical thinking [9], others offer a word of warning against returning to an era characterized by an ad-hoc, trial-and-error, and person-dependent ISD [11].

This body of literature provides a rich description of the challenging issues related to ISDM and, in spite of potential value, apparently the lack of it. In addition, although a sizable body of literature in the IS field that addresses various ISDM issues, the conceptualization and assessment of ISDM appears to be fragmented reflecting different disciplinary interests and perspectives. The purpose of this paper is to identify theoretical perspectives applied in the conceptualization of ISDM and to present a synthesized view of ISDM that reveals the complexities and ambiguities of a multifaceted phenomenon such as ISDM. The method for selecting and categorizing the literature is briefly described in the following section.

\section{Method}

We took ISDM as unit of analysis and used Google Scholar beta to search through web databases by combining following terms: systems development method or methodology, CASE tools and software process innovation. A type of snowball sampling technique was used as a next step in the data collection process in order to identify additional studies by consulting the references listed by the collected studies. Our exploratory search resulted into a collection of 547 sources. From the sizable and heterogeneous body of literature on ISDM we retained the studies that stated a theoretical perspective or presented a definition of ISDM. The remaining papers were analyzed and categorized based on the theoretical perspective on ISDM applied in the study. From the entire set of articles we identified four different theoretical perspectives on ISDM: 1) system, 2) structure, 3) innovation, and 3) knowledge. Since the conceptualization of ISDM was depicted differently within each perspective, we analyzed each conceptualization with regard to its scope in terms of content and features, and focus. The next section presents the results of our literature review.

\section{Theoretical Perspectives on ISDM}

One of the conceptualizations of ISDM follows from General System Theory [12], which helps to conceptualize and explain complex and abstract concepts by conceiving them as systems. A system is regarded as a collection of complementary and interacting components characterized by properties, capabilities, behavior and a boundary which separates it from its environment, designed to provide particular functionalities.

\subsection{ISDM as System}

The interpretation of ISDM as a system has been used by several authors. For instance an interpretation of Systems Methodology (SM) is epitomized as a:

"meta-system in its own right, incorporating skilled people, organization, tools, methods, techniques, etc. The SM is for individuals, teams and teams of teams, and can address problems from the small to the global, from the technological to the social and international." [5]

This starting point emphasizes the importance of understanding ISDM as an indivisible whole consisting of interacting but different types of components or subsystems. In the realm of engineering research the efforts have been directed toward providing procedural guidance and ISDM components like methods, techniques, and tools, in order to ensure efficiency and to:

- transform the software development from an ad hoc craft activity into a controlled and consistent production process [13]

- reduce software complexity, improve comprehensibility, promote reuse, and facilitate evolution [14]

Rather than considering human and societal components, the focus of the engineering view is on the development of generic artifacts. The field of method engineering has particularly focused on the development and composition of meta-methods [15].

In the area of IS the efforts have been concentrated on the interaction between artifacts and human and social components, as well as their properties. One field of research which has focused on both development and use of ISDM, or parts of it, by individual developers or groups of stakeholders, is the field of ISD research. An alternative way to define ISDM is as:

"an organized collection of concepts, methods (or techniques), beliefs, values, and normative principles supported by material resources ... and a codified set of goal-oriented 'procedures' which are intended to guide the work and cooperation of the various parties (stakeholders) involved in the building of an information systems application." [4] 
Despite ongoing issues and diverse interpretations, ISDM seems to include a collection of interrelated components such as

- Paradigms - a fundamental set of assumptions about knowledge, how to acquire it and about the physical and social world, that provide a way of thinking adopted by a professional community and allow its members to share similar perceptions and engage in commonly shared practices $[11,16]$

- Approaches - a set of goals, fundamental concepts and principles describing desirable features of a product and the development process model which represents the sequences of stages through which a system evolves. They influence the interpretations and actions in systems development and related methods, techniques, and tools [17]

- Methods-defines the tasks and activities to perform at least one complete phase of systems development being based typically on a particular approach and associated with a set of techniques, tools, and documentation $[17,18]$

- Techniques - procedure with a prescribed notation to perform and guide a development activity or a well-defined sequence of elementary operations that more or less guarantee the achievements of certain outcomes if executed correctly $[15,17]$

- Development tools-embody a particular methodology [19] and provide support in ISD processes [15,20], enforcing a particular set of steps and restricting developers' choices [19]

This perspective provides a description of the structure of ISDM and reveals the relation among ISDM components and its role, i.e., to support potential stakeholders in achieving their purposes, e.g., to develop an IS, to manage the development, or solve a problem. Alternative conceptualizations of ISDM have been suggested by applying or integrating various theories including structuration [21,22], innovation diffusion and adoption [23,24], knowledge diffusion and assimilation $[18,25,26]$, and learning $[3,8,27]$.

\subsection{ISDM as Structure}

ISDM is framed as a structure by Orlikowski [21,22], who argues that technology in general and ISDM in particular represent " a kind of structural properties of organizations developing and/or using technology. That is, technology embodies and hence is an instantiation of some of the rules and resources constituting the structure of an organization" [21]. Although the characteristics of ISDM are not explicitly discussed by the author, she makes a distinction between ISDM and CASE tools categorizing the first as a radical innovation and the latter as an incremental innovation. Hence, the implementation of an ISDM is considered to result in a radical change or reorientation of the organization, while the implementation of one of its components, e.g., the CASE tool component, is considered to result in an incremental change or variation. A product or process reorientation implies radical changes and might lead to resistance or even rejection [22].

Based on ISD empirical literature, is suggested that structures like ISDM might be invoked in the ISD context by stakeholders in learning or knowledge acquisition, conflict, negotiation, communication, influence, control, coordination, and persuasion. Although the structuration perspective does not insist on the content or properties of ISDM like the previous strand of research, it provides the view of ISDM as a means of change. [19]

\subsection{ISDM as Innovation}

Based on IS implementation model [28], which integrates IS implementation research and Diffusion of Innovation theory (DOI) [29], Huisman and Iivari found that along with other individaual, organizational, task, and environmental factors, the characteristics of ISDM perceived by systems developers to influence deployment of ISDM are:

- relative advantage-the degree to which an innovation is perceived as better than the idea it supersedes

- compatibility-the degree to which an innovation is perceived as consistent with existing values, past experience and needs of potential adopters

- $\quad$ trialability - the degree to which an innovation may be experimented with on a limited basis [24]

In a similar vein, but by combining DOI and Technology Acceptance Model, it is founded that, besides social pressure and organizational mandate, the characteristics of ISDM in terms of usefulness and compatibility are significant predictors for software developers' intention to use ISDM [23]. As showed by Venkatesh et al., who reviewed the user acceptance literature and formulated a Unified Theory of Acceptance and Use of Technology, the two constructs relative advantage and usefulness are similar and highlight individuals' performance expectancy [30]. In other words, at an individual unit of adoption, ISDM is perceived as a potential means, which, if used, enables gains in job performance. Moreover, the deployment of ISDM is perceived to improve communication and the career of individual developers [31]. The other two characteristics of ISDM, compatibility and trialability, are perceived to remove barriers and are therefore considered significant to facilitate intention 
formation and use.

An emphasis on individual developer perceptions is considered to be suitable to inform suppliers and managers about developers' beliefs about ISDM [23]. Yet, it is also considered too narrow to be of much use for organizations which adopt ISDM, because of its broadcasterreceiver perspective on communication, which underemphasizes the challenges and the role of adopters [32]. Therefore, researchers drawing on a knowledge dif- fusion perspective have centered their attention on analyzing the barriers that can impede the transfer or the integration of knowledge within or across organizations and communities.

\subsection{ISDM as Knowledge}

Drawing on a knowledge diffusion perspective, ISDM has been conceptualized as a source of knowledge which embodies "best practice" in ISD within an organization or IS community [2,18]. Accordingly, ISDM is regarded as an object that can be transferred through some form of communication from a supplier side [18], and assimilated through learning on the adopter side [25]. While these sides have two distinct roles in relation to the ISDM, in both cases the aim of the ISDM is to support or change the knowledge base and hence the practice within an organization or IS community. Based on a knowledge transfer perspective, it is argued that an external ISDM has to be adapted and incorporated into the specific knowledge base of an organization, forming in this way a new and organization-specific knowledge which represents an important core capability of a software development organization [1]. Focusing on the assimilation of software process innovations, which represent a class of complex innovation technologies, it is claimed that innovations of this type produce significant changes to a group's process for developing software applications. [33] Additionally, such innovations have the potential to increase returns on adoption having a high network potential but, when first introduced, generate high knowledge barriers and low performance relative to current best practices. According to the author, software process innovations impose a substantial knowledge burden on adopters impeding their deployment due to characteristics such as being:

- $\quad$ abstract-have an abstract and demanding scientific base, are eventually not physically observable, are more difficult to explain requiring a more active and prolonged learning period on the part of adopters in order to grasp and deploy them

- fragile-in the sense that they do not always operate as expected, have core features that must be replicated exactly to get expected results, create uncertainty for users, and require more resources and "hand holding" during deployment; performance in the laboratory represents a poor predictor of performance in practice

- $\quad$ trialable-are difficult to trial in a meaningful way, are difficult to introduce and install in stages, and in order to obtain benefits require that organizations compress all learning about them into a pre-implementation phase

- $\quad$ unpackaged-in the sense that adopters cannot treat the technology as a "black box", but must acquire broad tacit knowledge and procedural know-how to use it effectively, since the subcomponents of a technology cannot be tightly bundled into a turnkey product that can be introduced into organizations unchanged; users are confronted with learning the operational details of all components and their potential interaction

Regarded from a short-time perspective, it seems that ISDM creates problems for potential adopters who, as suggested by Beynon-Davies and Williams, need to unbundle the simplified and "black-boxed" solutions provided by the supply side, and integrate them with locally situated knowledge [18]. ISDM is considered as abstract, simplified knowledge detached from practice [3,8]. According to the authors, ISDM represents a means of formalization and an instrument that can be used by individuals for setting goals and making decisions [8], a means of transferring knowledge between experienced and novice developers, and templates to guide the development practice of new recruits [3]. The authors suggest that formalized ISDMs are rarely applied in their entirety and exactly as originally intended, but are uniquely enacted by developers in work practice, i.e., they are adapted or tailored differently in any development project.

ISDM has also been interpreted from a learning perspective [27]. Yet, according to the authors, ISDM is not a holder of knowledge but an evolving artifact which becomes understandable and meaningful as it is used. Accordingly, ISDM has been interpreted as a boundary object needed to mediate knowledge communication within as well as between communities [27]. The significant features of a boundary object, and hence of ISDM, that facilitate communication, coordination and collaboration are, according to Wenger:

- modularity - the object represents a combination of interrelated components which can be attended by the users

- abstraction-the object provides a common ground simultaneously allowing features specific to each user perspective

- adaptation - the product lends itself to different 


\section{activities}

- $\quad$ standardization-the resources in the product are formalized indicating how to be used in a particular context [34]

From this perspective, ISDM is not simply acquired but must be created and communicated through the interaction of members of a group who try to solve a particular work problem in practice [27]. Since ISDM represents the outcome of knowledge creation and learning, which are situated, the perception of, and interest in ISDM will therefore differ with regard to the position of the participants. This position is different from the one provided by the knowledge diffusion perspective, according to which the relationship between participants is based on a notion of control and formalization which provides a way of exchanging information, i.e., the ISDM is created by a supplier and communicated to potential adopters. Underpinned by a learning perspective, the studies frame ISDM as reminder that trigger knowledge and as guides to interpretation and action in IS development projects, thus representing a means of communication, coordination, control, and production.

Each perspective on ISDM identified in this literature review provides a different view on ISDM and its potential roles in different contexts. Table 1 summarizes the

Table 1.

\begin{tabular}{|c|c|c|c|}
\hline Conception & $\begin{array}{l}\text { Scope: contents } \\
\text { (1) \& features (2) }\end{array}$ & Focus & Sources \\
\hline System & $\begin{array}{l}\text { 1) paradigm, } \\
\text { approach, methods, } \\
\text { techniques, tools } \\
\text { 2) generic, } \\
\text { formalized, } \\
\text { structured, reusable }\end{array}$ & $\begin{array}{l}\text { Development } \\
\text { and deployment } \\
\text { of ISDM } \\
\text { components in } \\
\text { ISD projects }\end{array}$ & $\begin{array}{c}{[4,5,11,15,} \\
16,20,35,36]\end{array}$ \\
\hline Structure & $\begin{array}{l}\text { 1) methodology } \\
\text { and CASE tools } \\
\text { 2) - }\end{array}$ & $\begin{array}{l}\text { Deployment of } \\
\text { ISDM within } \\
\text { organization }\end{array}$ & {$[19,21,22]$} \\
\hline Innovation & $\begin{array}{l}\text { 1) } \quad- \\
\text { 2) relative } \\
\text { advantage, com- } \\
\text { patibility and } \\
\text { trialability }\end{array}$ & $\begin{array}{l}\text { Individuals' } \\
\text { deployment of } \\
\text { ISDM }\end{array}$ & {$[23,24,31]$} \\
\hline Knowledge & $\begin{array}{l}\text { 1) - } \\
\text { 2) abstract, } \\
\text { fragile, trialable, } \\
\text { unpackaged; } \\
\text { modularity, } \\
\text { abstraction, } \\
\text { adaptation, } \\
\text { standardization }\end{array}$ & $\begin{array}{l}\text { Deployment of } \\
\text { ISDM between } \\
\text { individuals as } \\
\text { well as within } \\
\text { or between } \\
\text { collectives (e.g., } \\
\text { groups, } \\
\text { organizations, } \\
\text { communities) }\end{array}$ & $\begin{array}{c}{[1,2,8,18,} \\
25-27]\end{array}$ \\
\hline
\end{tabular}

four theoretical perspectives applied in the conceptualization of ISDM along with their scope and focus and, due to space constraints, a limited example of sources.

\section{Discussions}

Although the literature review presented in this paper is not exhaustive, it highlights different ways in which ISDM has been conceptualized and addressed with regard to particular disciplinary concerns. The literature offers potential explanations for the dissension that continues to exist with regard to the nature and potential value of ISDM. Firstly, it reveals a shifted focus from the content of ISDM and its potential to support and guide the development of IS and management of the development process towards its characteristics and potential to change, i.e., innovation, learning, and structuration. Secondly, the assessment of ISDM deployment in isolation at individual [24], project [3], organization [21], or community [18] level, appears to be beneficial and to extend human capabilities by providing support for e.g., production, coordination, and collaboration. But, since these levels are related in a nested hierarchy, ISDM deployment might have not only intended but also unintended and, as indicated in the literature, unfortunately detrimental consequences, e.g., resistance, rejection, and knowledge barriers. For instance, efficiency gains expected to be achieved in the development of IS as a result of the introduction of ISDM within an organization might be lost because of a lack of compatibility with users' activities, values, or knowledge. Hence, a broad conceptualization of ISDM seems to be an appropriate point of departure in order to make sense of seemingly contradictory findings.

Such a conceptualization would suggest that the main purpose of ISDM, at least in general terms, is to extend human capabilities which would allow human agents to perform valuable functionings, i.e., those functionings that one has reason to value [37]. A capability, as conceived by Smith and Seward, who draw on realist social theory and critical realism, represents a configuration of three components, namely structure, agency, and cultural system, which are considered necessary for the achievement of associated functionings [37]. However, a capability set delineated by the interaction of these components embodies only potential functionings, while the outcomes of actual functionings are considered to be contingent on ambient conditions existent in the context where the capabilities are instantiated. By regarding ISDM as an intervention, the capabilities that such an intervention should aim to ensure are those that develop agential capacity and facilitate structural and cultural opportunities. Thus, we may assume that lack of attention to all these three components, i.e., structure, agency, and cultural system, will reduce the success of an ISDM 
intervention. In other words, in such an intervention it will not be enough to develop and provide sophisticated ISDM components or communicate and accumulate information and knowledge, but it will also be necessary to facilitate their deployment and learning.

\section{Conclusions}

The synthesis of the fairly large and heterogeneous literature on ISDM presented in this study reveals the complexities and ambiguities of a multifaceted phenomenon such as ISDM. Based on the literature review, four theoretical perspectives on ISDM were identified: 1) system, 2) structure, 3) innovation, and 4) knowledge. While each perspective regarded in isolation provides different overarching depictions of ISDM, together they provide a more nuanced picture of ISDM and its potential value in different contexts. Our literature review of ISDM is limited by our selective and incomplete use of prior literature. For instance, an additional theoretical perspective applied by Atkinson in order to explain the deployment of ISDM, i.e., the actor-network theory, emerged late in our work and we could not include it in our review [38]. Definitely, this should be examined in future research since it may reveal additional valuable insights into the role of ISDM within networks. We hope that our analysis will inspire other scholars and help guide conceptually sound investigations in order to reveal the scope, potential roles, and impact of ISDM.

\section{REFERENCES}

[1] P. Backlund, C. Hallenborg and G. Hallgrimsson, "Transfer of Development Process Knowledge through Method Adaptation and Implementation," Proceedings of the Eleventh European Conference in Information Systems, Naples, Italy, June 18-21, 2003, pp. 122-125.

[2] J. Iivari, R. Hirschheim and H. K. Klein, "Towards a Distinctive Body of Knowledge for Information Systems Experts: Coding ISD Process Knowledge in Two IS Journals," Information Systems Journal, Vol. 14, No. 4, 2004, pp. 313-342.

[3] B. Fitzgerald, N. L. Russo and E. Stolterman, "Information Systems Development: Methods in Action," McGrawHill Education, London, 2002.

[4] J. Iivari, R. Hirschheim and H. K. Klein, "A Dynamic Framework for Classifying Information Systems Development Methodologies and Approaches," Journal of Management Information Systems, Vol. 17, No. 3, 2000, pp. 179-218.

[5] D. K. Hitchins, "Systems Methodology," 2007. http:// www.hitchins.net/SysMethodology.html

[6] L. D. Introna and E. A. Whitley, "Against Method-Ism: Exploring the Limits of Method," Information Technology \& People, Vol. 10, No. 1, 1997, pp. 31-45.

[7] K. Lyytinen and D. Robey, "Learning Failure in Informa- tion Systems Development," Information Systems Journal, Vol. 9, No. 2, 1999, pp. 85-101.

[8] L. Mathiassen, "Reflective Systems Development," Scandinavian Journal of Information Systems, Vol. 10, No. 1-2, 1998, pp. 67-117.

[9] D. Truex, R. A. Baskerville and J. Travis, "Amethodical Systems Development: The Deferred Meaning of Systems Development Methods," Accounting, Management and Information Technology, Vol. 10, No. 1, 2000, pp. 53-79.

[10] C. Ciborra, "The Labyrinth of Information: Challenging the Wisdom of Systems," Oxford University Press, Oxford, 2007

[11] D. Avison and G. Fitzgerald, "Information System Development. Methodologies, Techniques and Tools," $4^{\text {th }}$ Edition, McGraw-Hill, New York, 2006.

[12] Von L. Bertalanffy, "General System Theory: Foundations, Development, Applications," George Braziller, New York, 1968.

[13] D. Kafura, "A Survey of Software Metrics," Proceedings of the 1985 ACM Annual Conference on the Range of Computing: Mid-80's Perspective, Denver, Colorado, 1985, pp. 502-506.

[14] P. Tarr, H. Ossher, W. Harrison and Jr. S. M. Sutton, "Degrees of Separation: Multi-Dimensional Separation of Concerns," Proceedings of the $21^{\text {st }}$ International Conference on Software Engineering, Los Angeles, CA, USA, May 1999, pp. 107-119.

[15] S. Brinkkemper, "Method Engineering: Engineering of Information Systems Development Methods and Tools," Information and Software Technology, Vol. 38, No. 4, 1996, pp. 275-280.

[16] R. Hirschheim and H. K. Klein, "Four Paradigms of Information Systems Development," Communications of the ACM, Vol. 32, No.10, 1989, pp. 1199-1216.

[17] M. Huisman and J. Iivari, "Deployment of Systems Development Methodologies: Perceptual Congruence between IS Managers and Systems Developers," Information \& Management, Vol. 43, No. 1, 2006, pp. 29-49.

[18] P. Beynon-Davies and M. D. Williams, "The Diffusion of Information Systems Development Methods," Journal of Strategic Information Systems, Vol. 12, No. 1, 2003, pp. 29-46.

[19] V. Sambamurthy and L. J. Kirsch, "An Integrative Framework of the Information Systems Development Process," Decision Sciences, Vol. 31, No. 2, 2000, pp. 391-411.

[20] P. Beynon-Davies, "Information Systems: An Introduction to Informatics in Organizations," Palgrave, Basingstoke, 2002.

[21] W. J. Orlikowski, "The Duality of Technology: Rethinking the Concept of the Technology in Organizations," Organization Science, Vol. 3, No. 3, 1992, pp. 398-427.

[22] W. J. Orlikowski, "CASE Tools as Organizational Change: Investigating Increment," MIS Quarterly, Vol. 17, No. 3, 
1993, pp. 309-340.

[23] B. C. Hardgrave, F. D. Davis and C. K. Riemenschneider, "Investigating Determinants of Software Developers' Intentions to Follow Methodologies," Journal of Management Information Systems, Vol. 20, No. 1, 2003, pp. 123-151.

[24] M. Huisman and J. Iivari, "The Individual Deployment of Systems Development Methodologies," Lecture Notes in Computer Science, Vol. 2348, 2002, pp. 134-150.

[25] R. G. Fichman and C. F. Kemerer, "The Assimilation of Software Process Innovations: An Organizational Learning Perspective," Management Science, Vol. 43, No. 10, 1997, pp. 1345-1363.

[26] E. Mustonen-Ollila and K. Lyytinen, "How Organizations Adopt Information Systems Process Innovations: A Longitudinal Analysis," European Journal of Information Systems, Vol. 13, No. 1, 2004, pp. 35-51.

[27] G. Fischer and J. Ostwald, "Knowledge Communication in Design Communities," In: R. Bromme, F. Hesse and H. Spada, Eds., Barriers and Biases in Computer-Mediated Knowledge Communication, Kluwer Academic Publishers, Netherlands, 2003, pp. 1-32.

[28] T. H. Kwon and R. W. Zmud, "Unifying the Fragmented Models of Information Systems Implementation," In: Boland, R. J. and Hirschheim, R. A. Eds., Critical Issues in Information Systems Research, John Wiley \& Sons, New York, 1987, pp. 227-251.

[29] E. M. Rogers, "Diffusion of Innovations," The Free Press, New York, 1995.

[30] V. Venkatesh, M. G. Morris, G. B. Davis and F. D. Davis, "User Acceptance of Information Technology: Toward a Unified View," MIS Quarterly, Vol. 27, No. 3, 2003, pp. 425-478.
[31] R. A. Johnson, B. C. Hardgrave and E. R. Doke, "An Industry Analysis of Developer Beliefs About ObjectOriented Systems Development," The DATA BASE for Advances in Information Systems, Vol. 30, No. 1, 1999, pp. 47-64.

[32] S. Newell, J. A. Swan and R. D. Galliers, "A Knowledge-Focused Perspective on the Diffusion and Adoption of Complex Information Technologies: The BPR Example," Information Systems Journal, Vol. 10, No. 3, 2000, pp. 239-259.

[33] R. G. Fichman, "The Assimilation and Diffusion of Software Process Innovations, Unpublished," Ph. D. Dissertation, MIT Sloan School of Management, 1995.

[34] E. Wenger, "Communities of Practice: Learning, Meaning, and Identity," Cambridge University Press, Cambridge, UK, 1998.

[35] C. Ghezzi, M. Jazayeri and D. Mandrioli, "Fundamentals of Software Engineering," $2^{\text {nd }}$ Edition, Prentice Hall, UK, 2003.

[36] K. Kumar and R. Welke, "Methodology Engineering: A Proposal for Situation-Specific Methodology Construction," In: W. Cotterman and J. Senn, Eds., Challenges and Strategies for Research in Systems Development, John Wiley \& Sons, New York, US, 1992, pp. 257-269.

[37] M. L. Smith and C. Seward, "Causal Theories and Citizenship: Bridging the Theory-Data Gap in Sen's Capability Approach," The 5th International Conference on the Capability Approach: Knowledge and Public Action, Paris, France, September 11-14, 2005.

[38] C. J. Atkinson, "The Soft Information Systems and Technologies Methodology: An Actor Network Contingency Approach to Integrated Development," European Journal of Information Systems, Vol. 9, No. 2, 2000, pp. 104-123. 